\title{
Inhibitory Effect of Ginsenoside Rg1 on Vascular Smooth Muscle Cell Proliferation Induced by PDGF-BB Is Involved in Nitric Oxide Formation
}

\author{
Jing Huang, ${ }^{1,2}$ Li-Sheng Li, ${ }^{1}$ Dan-Li Yang, ${ }^{1}$ Qi-Hai Gong, ${ }^{1}$ \\ Jiang Deng, ${ }^{1}$ and Xie-Nan Huang ${ }^{1}$ \\ ${ }^{1}$ Department of Pharmacology of Zunyi Medical College and the Key Laboratory of Basic Pharmacology of Guizhou, \\ Zunyi 563003, China \\ ${ }^{2}$ Department of Pharmacology, Mindong Medical School, 65 Manchun Road, Fujian, Fuan, 355017, China
}

Correspondence should be addressed to Xie-Nan Huang, huangxienan@yahoo.com.cn

Received 12 October 2011; Accepted 17 December 2011

Academic Editor: Youn Chul Kim

Copyright ( 92012 Jing Huang et al. This is an open access article distributed under the Creative Commons Attribution License, which permits unrestricted use, distribution, and reproduction in any medium, provided the original work is properly cited.

\begin{abstract}
Ginsenoside Rg1 (Rg1) has been reported to suppress the proliferation of vascular smooth muscle cells (VSMCs). This study aimed to observe the role of nitric oxide (NO) in Rg1-antiproliferative effect. VSMCs from the thoracic aorta of SD rats were cultured by tissue explant method, and the effect of $\operatorname{Rg} 1\left(20 \mathrm{mg} \cdot \mathrm{L}^{-1}, 60 \mathrm{mg} \cdot \mathrm{L}^{-1}\right.$, and $\left.180 \mathrm{mg} \cdot \mathrm{L}^{-1}\right)$ on platelet-derived growth factor-BB (PDGF-BB)-induced proliferation was evaluated by MTT assay. The cell cycle was analyzed by flow cytometry. For probing the mechanisms, the content of NO in supernatant and cGMP level in VSMCs was measured by nitric oxide kit and cGMP radioimmunity kit, respectively; the expressions of protooncogene c-fos and endothelial NO synthase (eNOS) mRNA in the VSMCs were detected by real-time RT-PCR; the intracellular free calcium concentration $\left(\left[\mathrm{Ca}_{2}{ }^{+}\right]_{\mathrm{i}}\right)$ was detected with Fura-2/AM-loaded VSMCs. Comparing with that in normal group, $\operatorname{Rg} 1180 \mathrm{mg} \cdot \mathrm{L}^{-1}$ did not change the absorbance of MTT and cell percent of $\mathrm{G}_{0} / \mathrm{G}_{1}, \mathrm{G}_{2} / \mathrm{M}$, and $\mathrm{S}$ phase in normal cells $(P>0.05)$. Contrarily, PDGF-BB could increase the absorbance of MTT $(P<0.01)$ and the percent of the $S$ phase cells but decrease the $G_{0} / G_{1}$ phase cell percent in the cell cycle, accompanied with an upregulating c-fos mRNA expression $(P<0.01)$, which was reversed by additions of $\operatorname{Rg} 1\left(20 \mathrm{mg} \cdot \mathrm{L}^{-1}, 60 \mathrm{mg} \cdot \mathrm{L}^{-1}\right.$, and $\left.180 \mathrm{mg} \cdot \mathrm{L}^{-1}\right)$. $\mathrm{Rg} 1$ administration could also significantly increase the NO content in supernatant and the cGMP level in VSMCs, as well as the eNOS mRNA expression in the cells, in comparison of that in the group treated with PDGF-BB alone $(P<0.01)$. Furthermore, $\mathrm{Rg} 1$ caused a further increase in the elevated $\left[\mathrm{Ca}^{2+}\right]_{\mathrm{i}}$ induced by PDGF-BB. It was concluded that $\mathrm{Rg} 1$ could inhibit the VSMC proliferation induced by PDGF-BB through restricting the $\mathrm{G}_{0} / \mathrm{G}_{1}$ phase to S-phase progression in cell cycle. The mechanisms may be related to the upregulation of eNOS mRNA and the increase of the formation of NO and cGMP.
\end{abstract}

\section{Introduction}

Ginsenoside $\operatorname{Rg} 1$ ( $\operatorname{Rg} 1)$ is believed to be one of the main active principles in ginseng (Panax ginseng C. A. Meyer), a traditional Chinese medicine used to enhance stamina and capacity to cope with fatigue as well as physical stress. It has been reported that $\mathrm{Rg} 1$ has many beneficial effects on several systems. For example, in cardiovascular system, Rg1 can ameliorate the ventricular remodeling induced by myocardial infarction [1] and the left ventricular hypertrophy induced by abdominal aorta coarctation [2] in rats and protect rat cardiomyocyte from hypoxia/reoxygenation oxidative injury [3]. Also, Rg1 has been reported to inhibit proliferation of vascular smooth muscle cells (VSMCs) induced by tumor necrosis factor- $\alpha$ and block the cell cycle in the G1-phase via depressing the signaling pathways of ERK, PI3K/PKB, and PKC $[4,5]$. However, cell proliferation is modulated by many factors, more studies should be done to elucidate the action mechanisms of the antiproliferative effect of Rg1.

Nitric oxide (NO) has been known to exert many different vasoprotective effects, such as inhibitions of platelet 
aggregation [6], leukocyte chemotaxis [7], and endothelial cell apoptosis [8]. For vasculature, mounting evidence has indicated that NO can inhibit VSMC proliferation in vitro and prevent the development of intimal hyperplasia after vascular injury in vivo [9-11]. The inhibitory effect of S-nitroso-N-acetylpenicillamine and sodium nitroprusside, the NO donors, on VSMC proliferation was thought via cGMP-dependent [12] and cGMP-independent [13-15] mechanisms. On the other hand, Rg1 has been reported to cause endothelial-dependent relaxation in the rat aorta [16], enhance endogenous NO production in human umbilical vein endothelial cells [17], rat kidney [18], and in porcine coronary arteries [19]. Interestingly, some pharmacological effects of Rg1 have been attributed to endogenous NO production, such as its improving effect on male mice copulatory behavior [20] and its protection against left ventricular hypertrophy induced by abdominal aorta coarctation in rats [21]. However, whether the antiproliferative effect of $\mathrm{Rg} 1$ on VSMC involves in endogenous NO production is unknown.

This study aimed to investigate the possible influence of Rg1 on the cell-cycle progression induced by platelet-derived growth factor-BB (PDGF-BB) and observe the role of $\mathrm{NO}$ in Rg1 antiproliferative effect on VSMC.

\section{Materials and Methods}

2.1. Materials and Animals. Rg1 (purity $>97 \%$ ) was obtained from Beijing Naturally Occurring Drugs Research Institute, China. Other reagents and their sources were mainly as follows: platelet-derived growth factor-BB (PDGF-BB) (Sigma-Aldrich Co. USA); 3-(4,5-dimethylthiazol-2-yl)-2,5diphenyltetrazolium bromide (MTT), propidium iodide (PI) dye, and Rnase A (Beijing Solarbio Science Technology Co. Beijing, China); Nitric oxide kit (Jiangsu Beyotime institute of Biotechnology. Jiangsu, China); cGMP radio-immunity kit (Beijing Puerweiye Biological Engineering Co. Beijing, China); $\beta$-actin primer endothelial nitric oxide synthase (eNOS) primer, c-fos primer and Cyclin D1 primer (Dalian TakaRa Biological Engineering Co. Dalian, China).

Sprague-Dawley rats $(150 \sim 200 \mathrm{~g})$ were purchased from the Animal Center of Institute of Surgery Research of the Third Military Medical University (Chongqing, China).

2.2. Cell Culture and Experimental Design. Rat VSMCs were isolated from rat thoracic aorta using the explanting technique [22]. Briefly, the aortic pieces (about $1 \mathrm{~mm}^{3}$ ) removed the endothelium, and adventitia were cultured in Dulbecco's modified Eagle's medium (Invitrogen Gibco, USA) containing $20 \%$ bovine serum, penicillin $100 \mathrm{U} / \mathrm{mL}$, streptomycin $100 \mu \mathrm{g} / \mathrm{mL}$ at $37^{\circ} \mathrm{C}$ in a humidified atmosphere of $95 \%$ air and $5 \% \mathrm{CO}_{2}$. After about 10 days, the cells were removed by trypsinization and successively subcultured. Cells from passages 3 to 10 were used for the experiments.

The VSMCs were randomly divided into six groups: Normal group (Normal): no drug was added; $\mathrm{N}+\mathrm{Rg} 1$ group $(\mathrm{N}+\mathrm{Rg} 1): \operatorname{Rg} 1180 \mathrm{mg} \cdot \mathrm{L}^{-1}$ was added in normal cells; PDGF-BB model group (Model): PDGF-BB $25 \mu \mathrm{g} \cdot \mathrm{L}^{-1}$ was added in normal grown cells; Rg1 low-dose group (Rg1-L), middle-dose group (Rg1-M), and high-dose group (Rg1-H):
Rg1 $20 \mathrm{mg} \cdot \mathrm{L}^{-1}, 60 \mathrm{mg} \cdot \mathrm{L}^{-1}, 180 \mathrm{mg} \cdot \mathrm{L}^{-1}$ were added, respectively, to the cells treated with $25 \mu \mathrm{g} \cdot \mathrm{L}^{-1} \mathrm{PDGF}-\mathrm{BB}$. The above concentrations of PDGF-BB or Rg1 used in each group were final concentration.

2.3. Assessment of VSMC Proliferation by MTT Assay. The rat VSMCs were harvested by trypsinization and plated in a 96well plate at a density of $1 \times 10^{5}$ cells/mL. PDGF-BB and Rg1 were added to each well as the mention in experimental design (PDGF-BB was added at $30 \mathrm{~min}$ after the addition of Rg1). Briefly, MTT assays were carried out as follow: VSMCs were grown in $100 \mu \mathrm{L}$ medium at $37^{\circ} \mathrm{C}$ under $5 \% \mathrm{CO}_{2}$ for $24 \mathrm{~h}$ in 96-well plates, followed by a incubation with $10 \mu \mathrm{L}$ $\operatorname{MTT}\left(5 \mathrm{~g} \cdot \mathrm{L}^{-1}\right)$ for $4 \mathrm{~h}$. Then $100 \mu \mathrm{L}$ (dimethyl sulfoxide) DMSO were added to each well, and an absorbance at $490 \mathrm{~nm}$ was read on a Microplate reader.

2.4. Cell-Cycle Analysis Using Flow Cytometry (FCM). VSMCs were seeded in six-well plastic culture dishes at a density of $5 \times 10^{5}$ cells/mL, PDGF-BB and Rg1 were added as MTT assay after cell synchronization and cultured for $24 \mathrm{~h}$. Thereafter, VSMCs were harvested by trypsinization and collected from the six-well plate, placed in Eppendorf tubes and washed with $4^{\circ} \mathrm{C}$ PBS twice, then fixed with $2 \mathrm{~mL} 70 \%$ ice-ethanol overnight. After centrifugalization, the VSMCs were washed with PBS twice again. Finally, the DNA contents of VSMCs were determined by PI staining and FCM analysis.

2.5. Real-Time RT-PCR Analysis of c-Fos, and eNOS mRNA. VSMCs were seeded in $25 \mathrm{~mL}$ culture flask at a density of $1 \times 10^{5}$ cells/flask, total RNA was isolated by using the TRIzol (MRC Co., Cincinnati, USA) method after 24 h of PDGF-BB and Rg1 action. Two-step reverse-transcription polymerase chain reaction was used to detect the expression by iCycle iQ Real-Time PCR Detection System (BIO-RAD Co., California, USA), with SYBR Green PCR Master Mix (ABI Co., Foster, USA). The Primers were designed with Express Software and synthesized by TaKaRa Biological Engineering Company (Dalian, China). The following Primers were used: c-fos (GenBank accession no. RA_011723): forward primer $\left(5^{\prime}-3^{\prime}\right)$ CCC GGC ATC CTT ATT CAA TTA TCA, reverse primer $\left(5^{\prime}-3^{\prime}\right)$ GTG TTA TCC CAC AGC ATG TCA ACA G; eNOS (GenBank accession no. NM_021838): forward primer (5'$\left.3^{\prime}\right)$ AGC TGG ATG AAG CCG GTG AC, reverse primer (5'$3^{\prime}$ ) CCT CGT GGT AGC GTT GCT GA; $\beta$-actin (GenBank accession no. NM_031144): forward primer $\left(5^{\prime}-3^{\prime}\right) \mathrm{GGC}$ CAA CCG TGA AAA GAT GA, reverse primer $\left(5^{\prime}-3^{\prime}\right)$ CAG CCT GGA TGG CTA CGT ACA. The reaction conditions were $95^{\circ} \mathrm{C} 10 \mathrm{~min} 1 \mathrm{cycle} ; 95^{\circ} \mathrm{C} 15 \mathrm{~s}$, annealing temperature $1 \mathrm{~min}, 40$ cycles. The threshold cycle $(\mathrm{Ct})$ values of target genes were normalized with $\beta$-actin of the same sample, and expressed as were relative to controls.

2.6. Measurements of NO Content in Supernatant and cGMP Level in VSMCs. The measurements of $\mathrm{NO}$ content in supernatant and cGMP level in VSMCs were undertaken according to the manufacturer's instructions in the assay kits. VSMC culture cell synchronization and experimental design were in accordance with MTT assay. 
2.7. Measurement of the Intracellular Free Calcium Concentration $\left(\left[\mathrm{Ca}^{2+}\right]_{i}\right)$ in VSMCs. The cultured VSMCs were centrifuged at $150 \mathrm{~g}$ for $5 \mathrm{~min}$ at room temperature.The supernatant was discarded, and the cells were washed twice with Hanks solution (in mmol/L: $\mathrm{NaCl} 137.0, \mathrm{CaCl}_{2}$ 1.3, $\mathrm{KCl} 5.4, \mathrm{MgSO}_{4}$ 0.8, $\mathrm{NaHPO}_{4} 0.38, \mathrm{KH}_{2} \mathrm{PO}_{4}$ 0.44, $\mathrm{NaHCO}_{3}$ 4.2, sucrose 5.6, BSA $0.2 \%$; pH 7.4), then the cells were incubated in Hanks solution containing $3 \mu \mathrm{mol} / \mathrm{L}$ Fura2/AM for $40 \mathrm{~min}$ at $37^{\circ} \mathrm{C}$, followed by washing twiced to remove the extracellular dye. Finally, the cell number was adjusted to $1 \times 10^{-6}$ cells $/ \mathrm{mL}$ for measurement of $\left.\left[\mathrm{Ca}^{2+}\right)\right]_{\mathrm{i}}$.

The fluorescence value from $1 \mathrm{~mL}$ cell suspension was measured by a RF-5000 dual-wavelength spectrofluorometer (Shimadzu Company, Japan) with excitation wavelengths at $340 / 380 \mathrm{~nm}$ and emission wavelength at $480 \mathrm{~nm}$. The ratio $(R)$ of the fluorescence signals at $340 / 380(\mathrm{~nm})$ was calculated automatically, and the maximal $R$ value $\left(R_{\max }\right)$ and minimal $R$ value $\left(R_{\min }\right)$ were determined by the addition of $10 \mu \mathrm{L} 10 \%$ TritonX-100 (final concentration $0.1 \%$ ) and $10 \mu \mathrm{L} 500 \mathrm{mmol} / \mathrm{L}$ EGTA (final concentration $5 \mathrm{mmol} / \mathrm{L}$ ), respectively. The $\left[\mathrm{Ca}^{2+}\right]_{\mathrm{i}}$ was calculated by the formula described before [22] $\left.\left[\mathrm{Ca}^{2+}\right)\right]_{\mathrm{i}}=224 \times\left[\left(R-R_{\min }\right) /\left(R_{\max }-\right.\right.$ $R)] \times F D / F S$, where $F D$ and $F S$ are the fluorescence proportionality coefficients obtained at $380 \mathrm{~nm}$ under $R_{\min }$ and $R_{\max }$ conditions, respectively. The number 224 is the $K_{\mathrm{D}}$ value of Fura-2/AM. To observe the possible influence of Rg1 on the elevated $\left.\left[\mathrm{Ca}^{2+}\right)\right]_{\mathrm{i}}$ induced by PDGF-BB, Rg1 was added before the addition of this growth factor, and the fluorescence intensity was detected at 5 min after PDGF-BB addition.

2.8. Statistical Analysis. All data are presented as mean \pm S.E.M. and were analyzed by the one-way ANOVA followed by Student's $t$-test (two-tails) with the SPSS 13.0 software (SPSS Inc, Chicago, Illinois, USA), and significance was set at $P<0.05$.

\section{Results}

3.1. Effect of Rg1 on MTT Assay in Rat VSMCs. In normal cells without any treatment of growth factor, $\operatorname{Rg} 1180 \mathrm{mg} \cdot \mathrm{L}^{-1}$ did not change the MTT absorbance, while the addition of PDGF-BB could significantly increase the absorbance in MTT assay $(P<0.01)$, which tended to be inhibited by an addition of $\mathrm{Rg} 120 \mathrm{mg} \cdot \mathrm{L}^{-1}(P>0.05)$, and was remarkably inhibited by $\mathrm{Rg} 160 \mathrm{mg} \cdot \mathrm{L}^{-1}$ and $180 \mathrm{mg} \cdot \mathrm{L}^{-1}(P<0.05$ and $P<0.01)$, suggesting the antiproliferating effect of $\operatorname{Rg} 1$ on VSMCs (Figure 1).

\subsection{Effect of Rg1 on the Cell Cycle Induced by PDGF-BB in Rat} VSMCs. The results shown in Figure 2 demonstrated that Rg1 $180 \mathrm{mg} \cdot \mathrm{L}^{-1}$ had no any effect on the growth of normal cells, while PDGF-BB could significantly increase the percent of S-phase cells and degrade the $G_{0} / G_{1}$-phase cell percent in the cell cycle $(P<0.01)$ administration of $\operatorname{Rg} 1\left(20 \mathrm{mg} \cdot \mathrm{L}^{-1}\right.$, $\left.60 \mathrm{mg} \cdot \mathrm{L}^{-1}, 180 \mathrm{mg} \cdot \mathrm{L}^{-1}\right)$ at $30 \mathrm{~min}$ after PDGF-BB addition could markedly decrease the $S$-phase cell percent and upgrade the $G_{0} / G_{1}$ phase percent in the cell cycle. The data suggested that Rg1 could inhibit the VSMC proliferation

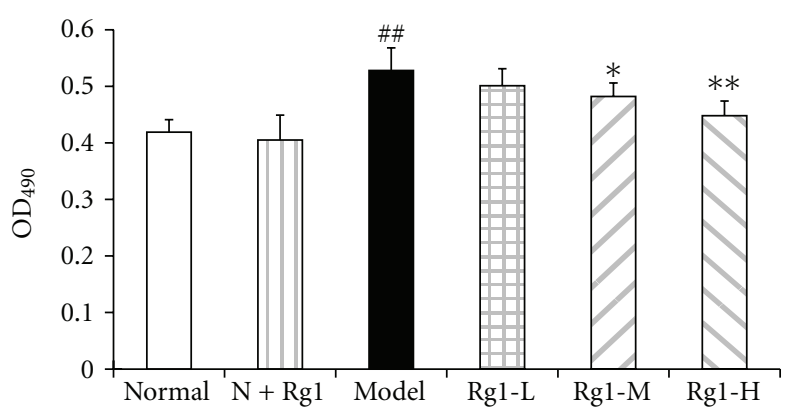

FIGURE 1: Effect of Rgl on PDGF-BB-induced VSMC proliferation (MTT assay, $\bar{x} \pm s, n=7$ ). The VSMCs were cultured for 24 h. Normal: vehicle; $\mathrm{N}+\operatorname{Rg} 1: \operatorname{Rg} 1180 \mathrm{mg} \cdot \mathrm{L}^{-1}$; model: PDGFBB $25 \mu \mathrm{g} \cdot \mathrm{L}^{-1}$; $\operatorname{Rg} 1-\mathrm{L}: \operatorname{Rg} 120 \mathrm{mg} \cdot \mathrm{L}^{-1}+\mathrm{PDGF}-\mathrm{BB} 25 \mu \mathrm{g} \cdot \mathrm{L}^{-1}$; Rg1-M: $\operatorname{Rg} 160 \mathrm{mg} \cdot \mathrm{L}^{-1}+\mathrm{PDGF}-\mathrm{BB} 25 \mu \mathrm{g} \cdot \mathrm{L}^{-1} ; \mathrm{Rg} 1-\mathrm{H}: \operatorname{Rg} 1$ $180 \mathrm{mg} \cdot \mathrm{L}^{-1}+\mathrm{PDGF}-\mathrm{BB} 25 \mu \mathrm{g} \cdot \mathrm{L}^{-1}$. Data were mean \pm S.E.M. \#\# Significant difference from normal control at $P<0.01^{*}$ significant difference from model control at $P<0.05$, and $* *$ significant difference from model control at $P<0.01$.

induced by PDGF-BB through restricting the $G_{0} / G_{1}$-phase to $S$-phase progression in cell cycle.

\subsection{Effect of Rg1 on the Expression of c-Fos and eNOS mRNA.} The results from real-time RT-PCR assay indicated that PDGF-BB could elevate the $\mathrm{c}$-fos mRNA expression by about 10 times of that in the normal control, and Rg1 could significantly blunt the c-fos expression $(P<0.01)$. On the other hand, addition of PDGF-BB decreased the expression of eNOS mRNA by about $67 \%$, and Rg1 could reverse the decreasing eNOS expression in a concentration-dependent manner $(P<0.01)$ (Figure 3).

3.4. Changes of NO Content in Supernatant and cGMP Level in VSMCs. As shown in Figure 4(a), PDGF-BB could significantly degrade the content of $\mathrm{NO}$ in the supernatant of the cultured VSMCs $(P<0.01)$, the addition of the low concentration of $\operatorname{Rg} 1\left(20 \mathrm{mg} \cdot \mathrm{L}^{-1}\right)$ tended to increase the NO content $(P>0.05)$, and the higher concentrations of Rg1 $\left(60 \mathrm{mg} \cdot \mathrm{L}^{-1}, 180 \mathrm{mg} \cdot \mathrm{L}^{-1}\right)$ could significantly elevate the content of NO $(P<0.05$ or $P<0.01)$. Consistent with the changes of NO content in supernatant, the cGMP level in VSMCs was also decreased by PDGF-BB $(P<0.01)$ and was markedly increased by additions of all three concentrations of $\operatorname{Rg} 1(P<0.05$ or $P<0.01)$ (Figure $4(b))$.

3.5. Change of $\left[\mathrm{Ca}^{2+}\right]_{i}$ in VSMCs by Rg1 treatment. The $\left[\mathrm{Ca}^{2+}\right]_{\mathrm{i}}$ levels of VSMCs were detected at 3 minutes after the addition of PDGF-BB or at 33 minutes after Rg1administration. In our experimental conditions, the basal $\left[\mathrm{Ca}^{2+}\right]_{\mathrm{i}}$ was about $120 \mathrm{nmol} / \mathrm{L}$ in normal VSMCs; it tended to increase by $\mathrm{Rg} 1180 \mathrm{mg} \cdot \mathrm{L}^{-1}(P>0.05)$, and was elevated to $182 \mathrm{nmol} / \mathrm{L}$ by the addition of PDGF-BB $25 \mu \mathrm{g} \cdot \mathrm{L}^{-1}(P<$ $0.05)$. When Rg1 was administered at 30 minutes before PDGF-BB addition, it could cause a further increase in the elevated $\left[\mathrm{Ca}^{2+}\right]_{\mathrm{i}}$ induced by this growth factor in a dosedependent manner (Figure 5). 

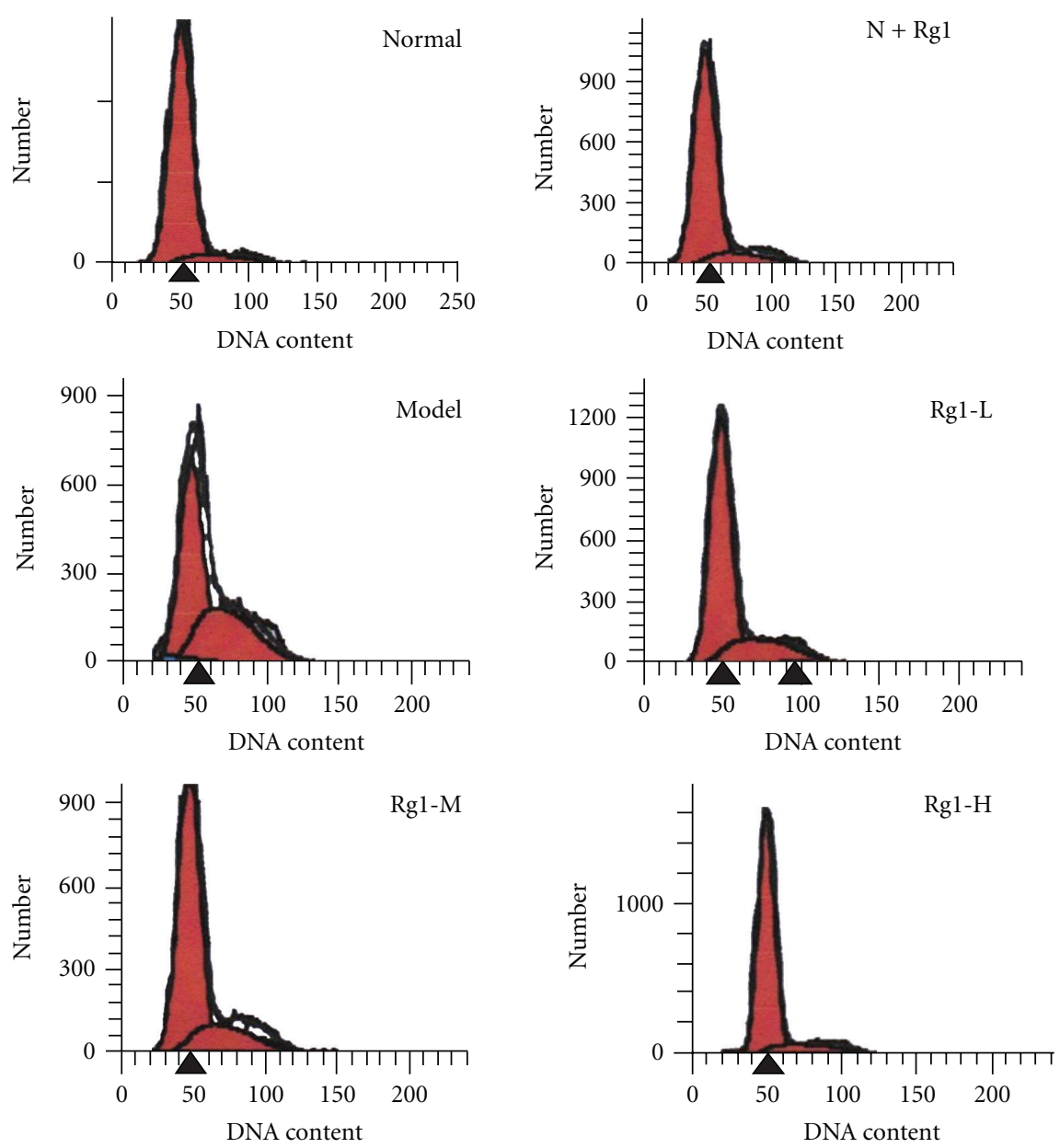

(a)
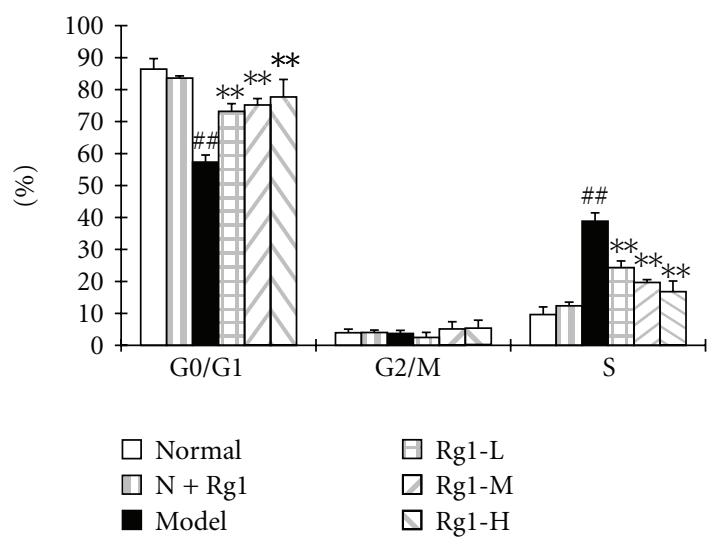

(b)

FIGURE 2: Effect of Rg1 on the VSMC cell cycle in the presence of PDGF-BB $(\bar{x} \pm s, n=4 \sim 6, \%)$. A: representative results of flow cytometry measurements to determine the cell-cycle stages of VSMCs; B:percentage of cells in each phase of the cell cycle. Normal: vehicle; $\mathrm{N}+\operatorname{Rg} 1: \operatorname{Rg} 1180 \mathrm{mg} \cdot \mathrm{L}^{-1}$; model: PDGF-BB $25 \mu \mathrm{g} \cdot \mathrm{L}^{-1} ; \mathrm{Rg} 1-\mathrm{L}: \operatorname{Rg} 120 \mathrm{mg} \cdot \mathrm{L}^{-1}+\mathrm{PDGF}-\mathrm{BB} 25 \mu \mathrm{g} \cdot \mathrm{L}^{-1} ; \mathrm{Rg} 1-\mathrm{M}: \mathrm{Rg} 160 \mathrm{mg} \cdot \mathrm{L}^{-1}+\mathrm{PDGF}-$ BB $25 \mu \mathrm{g} \cdot \mathrm{L}^{-1} ; \mathrm{Rg} 1-\mathrm{H}: \operatorname{Rg} 1180 \mathrm{mg} \cdot \mathrm{L}^{-1}+\mathrm{PDGF}-\mathrm{BB} 25 \mu \mathrm{g} \cdot \mathrm{L}^{-1}$. Data were mean \pm S.E.M. ${ }^{\#}$ Significant difference from normal control at $P<0.01 ; *$ significant difference from model control at $P<0.01$. 

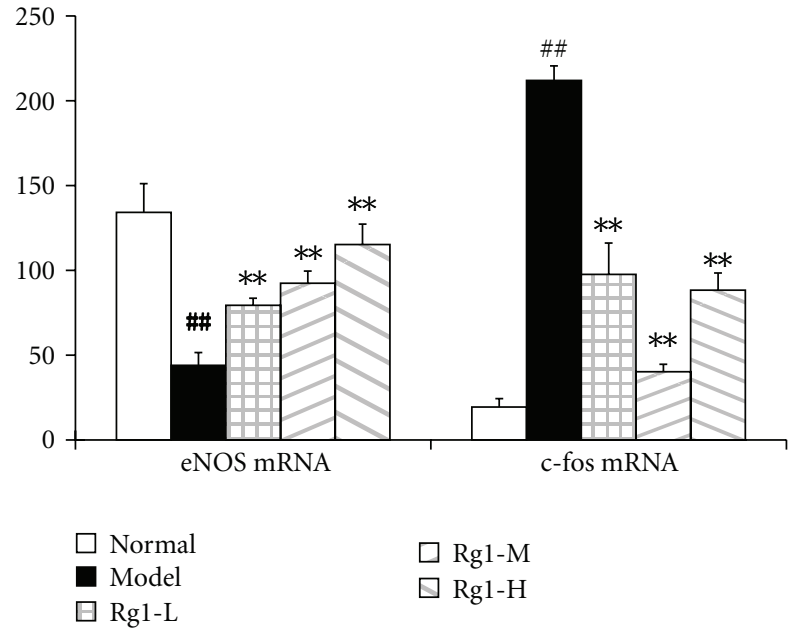

Figure 3: Effects of Rg1 on the changes of expressions of c-fos and eNOS mRNA induced by PDGF-BB in VSMC ( $\bar{x} \pm s, n=3)$; realtime RT-PCR analysis of c-fos, and eNOS mRNA were performed after $24 \mathrm{~h}$ of PDGF-BB and Rgl actions in VSMCs. Normal : vehicle; model: PDGF-BB $25 \mu \mathrm{g} \cdot \mathrm{L}^{-1} ; \operatorname{Rg} 1-\mathrm{L}: \operatorname{Rg} 120 \mathrm{mg} \cdot \mathrm{L}^{-1}+$ PDGF-BB $25 \mu \mathrm{g} \cdot \mathrm{L}^{-1} ; \operatorname{Rg} 1-\mathrm{M}: \operatorname{Rg} 160 \mathrm{mg} \cdot \mathrm{L}^{-1}+\mathrm{PDGF}-\mathrm{BB} 25 \mu \mathrm{g} \cdot \mathrm{L}^{-1} ; \mathrm{Rg} 1-$ $\mathrm{H}: \operatorname{Rg} 1180 \mathrm{mg} \cdot \mathrm{L}^{-1}+\mathrm{PDGF}-\mathrm{BB} 25 \mu \mathrm{g} \cdot \mathrm{L}^{-1}$. Data were mean \pm S.E.M. ${ }^{\#}$ Significant difference from normal control at $P<0.01$; ** significant difference from model control at $P<0.01$.

\section{Discussion}

VSMC proliferation has been known to be an important component of vessel wall remodelling in response to injury, such as after angioplasty and during atherosclerosis formation [23, 24]. The development of highly effective antiproliferative drugs is necessary for the prevention and treatment of hypertrophic vascular diseases. Rg1 has been reported to inhibit TNF- $\alpha$-induced human arterial smooth muscle-cell proliferation and cause cell-cycle arrest in G1 phase [4], and PDGF-BB is known to be a mitogen involved in the development of vascular proliferative lesions observed in atherosclerosis and in restenosis after angioplasty $[25,26]$. In the present study, we further certified the antiproliferative effect of $\operatorname{Rg} 1$ on the VSMCs from ratthoracic aorta, using PDGF-BB to induce cell proliferation. Our study also certified that $\operatorname{Rg} 1$ could cause $G_{0} / G_{1}$ cell cycle arrest in rat VSMCs, which was very consistent with the report [4]. Furthermore, VSMC proliferation has been known to be promoted by the concerted action of several distinct signal transduction pathways, such as phospholipase $\mathrm{C}$ isoforms and mitogen-activated protein kinase (MAPK) cascade [27-29]. The final result of these pathways activation is transcription and activation of the early response genes cfos and c-jun. Rg1 has been reported to inhibit the PKC and MAPK signalings in TNF- $\alpha$-treated human arterial smooth muscle cells $[4,5]$; in this study, we found that $\operatorname{Rg} 1$ could also significantly inhibit the elevated c-fos mRNA expression induced by PDGF-BB, which might be the result of the transduction pathway inhibitions.

Because NO has been shown to play diverse roles in the physiology and pathophysiology of the cardiovascular

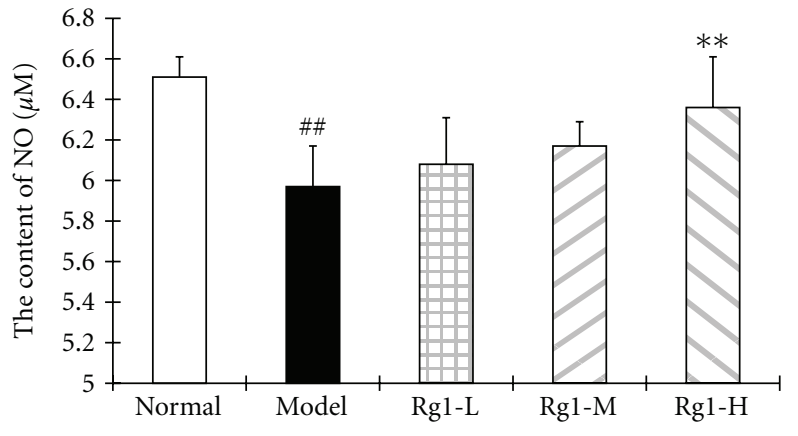

(a)

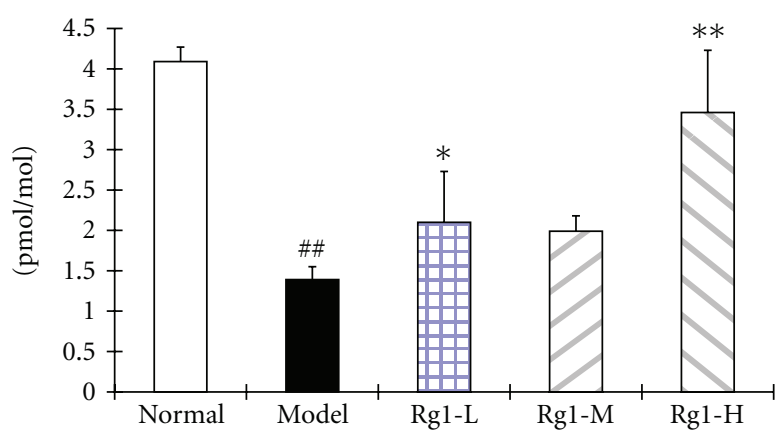

(b)

Figure 4: Effects of Rg1 on the NO content in supernatant (a) and cGMP level in cultured VSMCs (b) in the presence of PDGF-BB. VSMCs were cultured for $24 \mathrm{~h}$, the NO content in supernatant and cGMP level in the cells were determined with the corre- sponding Kits. Normal: vehicle; model: PDGF-BB $25 \mu \mathrm{g} \cdot \mathrm{L}^{-1}$; Rg1-L: Rg1 $20 \mathrm{mg} \cdot \mathrm{L}^{-1}+\mathrm{PDGF}-\mathrm{BB} 25 \mu \mathrm{g} \cdot \mathrm{L}^{-1} ; \operatorname{Rg} 1-\mathrm{M}: \operatorname{Rg} 160 \mathrm{mg} \cdot \mathrm{L}^{-1}+$ PDGF-BB $25 \mu \mathrm{g} \cdot \mathrm{L}^{-1} ; \operatorname{Rg} 1-\mathrm{H}: \operatorname{Rg} 1180 \mathrm{mg} \cdot \mathrm{L}^{-1}+$ PDGF-BB

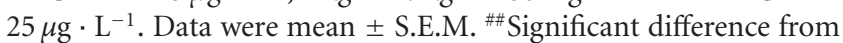
normal control at $P<0.01$; ${ }^{*}$ significant difference from model control at $P<0.01$.

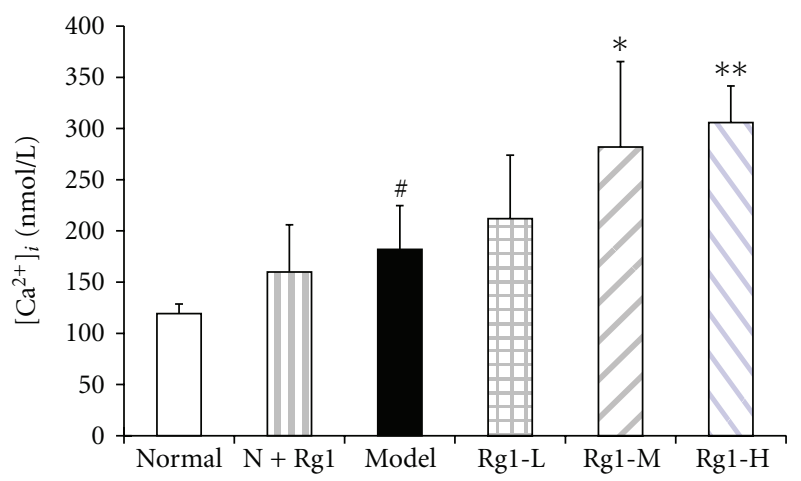

FIgURE 5: Effect of Rg1 on the intracellular free $\mathrm{Ca}^{2+}$ concentration $\left(\left[\mathrm{Ca}^{2+}\right]_{\mathrm{i}}\right)$ of VSMCs. The $\left[\mathrm{Ca}^{2+}\right]_{\mathrm{i}}$ was detected after 3 minutes of PDGF-BB addition with Fura-2/AM loaded VSMCs, and $\mathrm{Rg} 1$ administrations were performed before 30 minutes of the addition of PDGF-BB. Normal: vehicle; model:PDGFBB $25 \mu \mathrm{g} \cdot \mathrm{L}^{-1} ; \operatorname{Rg} 1-\mathrm{L}: \operatorname{Rg} 120 \mathrm{mg} \cdot \mathrm{L}^{-1}+\mathrm{PDGF}-\mathrm{BB} 25 \mu \mathrm{g} \cdot \mathrm{L}^{-1}$; Rg1-M:Rg1 $60 \mathrm{mg} \cdot \mathrm{L}^{-1}+\mathrm{PDGF}-\mathrm{BB} 25 \mu \mathrm{g} \cdot \mathrm{L}^{-1} ; \mathrm{Rg} 1-\mathrm{H}: \operatorname{Rg} 1$ $180 \mathrm{mg} \cdot \mathrm{L}^{-1}+\mathrm{PDGF}-\mathrm{BB} 25 \mu \mathrm{g} \cdot \mathrm{L}^{-1}$. Data were mean \pm S.E.M. \#Significant difference from normal control at $P<0.05$; * significant difference from model control at $P<0.05,{ }^{*}$ Significant difference from model control at $P<0.01$. 
system, including inhibition of VSMC proliferation [9], and Rg1 has been known to promote the endogenous NO production in many tissues [16-21], in the present study, we have emphatically observed the influences of Rg1 on the NO content in supernatant, cGMP level and $\left[\mathrm{Ca}^{2+}\right]_{i}$ in VSMCs, as well as the expression of eNOS in the cells, to clarify the relationship between the antiproliferative effect of $\operatorname{Rg} 1$ and NO formation.

It is known that NO stimulates cytosolic soluble guanylyl cyclase to increase cGMP formation, which accompany the activation of cGMP-dependent protein kinase [30, 31] and it has also been known that the NO donors, such as S-nitroso$\mathrm{N}$-acetylpenicillamine (SNAP) and sodium nitroprusside, inhibit VSMC proliferation by cGMP-dependent [12] and cGMP-independent [13-15] mechanisms. In our study, we found that both NO content in supernatant and cGMP level in VSMCs were degraded by addition of PDGF-BB and elevated by Rg1-treatment. The results seemed to suggest that the increase in cGMP level was from the NO formation after Rg1 addition. Consistent with above results, we also found that Rg1 could significantly upregulate the expression of eNOS in VSMCs in a concentration-dependent manner. Taking the above results together, it appears to be possible that $\mathrm{Rg} 1$ promotes the NO formation through upregulating the NOS (at least for eNOS) expression, and to stimulate cytosolic soluble guanylyl cyclase to increase cGMP formation, then the NO itself and cGMP participate the inhibition on VSMC proliferation. It has been reported that in human umbilical vein endothelial cells, Rg1 can downregulate miR214 (a microRNA related closely to eNOS) expression, leading to an increase in eNOS expression [32]. Whether miR-214 downregulation is involved in the up-regulation of eNOS in this model used in our work remains to be studied.

Notably, the preceding studies indicate that $\mathrm{NO}$ inhibits VSMC proliferation by preventing an increase in cell $\left[\mathrm{Ca}^{2+}\right]_{\mathrm{i}}$ [33], and $\mathrm{Rg} 1$ has been reported to inhibit $\mathrm{Ca}^{2+}$ influx in the neurons suffered from hypoxic-ischemic injury [34]. Because vasoconstrictor agonists and growth factors generally cause an increase in cytosolic $\mathrm{Ca}^{2+}$ within seconds to minutes [33], we detected the $\left[\mathrm{Ca}^{2+}\right]_{\mathrm{i}}$ level of VSMCs at 3 minutes after addition of PDGF-BB. Surprisingly, the result showed that in our experimental conditions, Rg1 (administered at 30 minutes before PDGF-BB addition) could cause a further increase in the elevated $\left[\mathrm{Ca}^{2+}\right]_{i}$ induced by PDGFBB. Obviously, the increased $\left[\mathrm{Ca}^{2+}\right]_{i}$ could not be attributed to $\mathrm{NO}$ formation, and might be the direct action of $\mathrm{Rg} 1$ to $\mathrm{Ca}^{2+}$ influx or $\mathrm{Ca}^{2+}$ release from the endoplasmic reticulum. We conjectured that the NO formation-promoting effect of Rg1 might be not strong enough to reduce the $\left[\mathrm{Ca}^{2+}\right]_{\mathrm{i}}$ level of VSMCs at the $\mathrm{Ca}^{2+}$-detection time ( 3 minutes after PDGF-BB addition), and the antiproliferative effect of $\mathrm{Rg} 1$ via promoting NO-formation perhaps occurred when larger amount of eNOS expression had been restored. On the other hand, some investigators reported that the $\mathrm{Ca}^{2+}$-increasing agents including $\mathrm{Ca}^{2+}$ ionophore $\mathrm{A} 23187$, ionomycin, cyclopiazonic acid, and di-tert-butylhydroquinone had little effect on proliferation of VSMCs, and they thought that an increase in $\left[\mathrm{Ca}^{2+}\right]_{\mathrm{i}}$ per se does not appear to be important in VSMC replication [35]. What is the relationship between the
$\mathrm{Ca}^{2+}$-increasing effect of $\mathrm{Rg} 1$ and its VSMC proliferationinhibiting effect remained to be studied.

It is concluded that one of the mechanisms for $\mathrm{Rg} 1$ inhibition on VSMC proliferation is related to the upregulation of eNOS mRNA and increases the formation of $\mathrm{NO}$ and cGMP.

\section{Acknowledgment}

This work was supported by the Governor Talent Foundation of Guizhou province, China, no. 2007-53.

\section{References}

[1] H. Hin, Z. Liu, F. Li et al., "Ginsenoside Rg1 enhances angiogenesis and amelioeates ventricular remodeling in a rat model of myocardial infarction," Journal of Molecular Medicine, vol. 89, no. 4, pp. 363-375, 2011.

[2] J. Deng, X. T. Lv, Q. Wu, and X. N. Huang, “Ginsenoside Rg1 inhibits rat left ventricular hypertrophy induced by abdominal aorta coarctation: involvement of calcineurin and mitogenactivated protein kinase signalings," European Journal of Pharmacology, vol. 608, no. 1-3, pp. 42-47, 2009.

[3] D. Zhu, L. Wu, C. R. Li et al., "Ginsenoside Rg1 protects rat cardiomyocyte from hypoxia/reoxygenation oxidative injury via antioxidant and intracellular calcium homeostasis," Journal of Cellular Biochemistry, vol. 108, no. 1, pp. 117-124, 2009.

[4] Z. C. Ma, Y. Gao, Y. G. Wang, H. L. Tan, C. R. Xiao, and S. Q. Wang, "Ginsenoside Rg1 inhibits proliferation of vascular smooth muscle cells stimulated by tumor necrosis factor- $\alpha$," Acta Pharmacologica Sinica, vol. 27, no. 8, pp. 1000-1006, 2006.

[5] H. S. Zhang and S. Q. Wang, "Ginsenoside Rg1 inhibits tumor necrosis factor- $\alpha$ (TNF- $\alpha$ )- induced human arterial smooth muscle cells (HASMCs) proliferation," Journal of Cellular Biochemistry, vol. 98, no. 6, pp. 1471-1481, 2006.

[6] M. W. Radomski, R. M. J. Palmer, and S. Moncada, "Endogenous nitric oxide inhibits human platelet adhesion to vascular endothelium," The Lancet, vol. 2, no. 8567, pp. 1057-1058, 1987.

[7] P. Kubes, M. Suzuki, and D. N. Granger, "Nitric oxide: an endogenous modulator of leukocyte adhesion," Proceedings of the National Academy of Sciences of the United States of America, vol. 88, no. 11, pp. 4651-4655, 1991.

[8] E. Tzeng, Y. M. Kim, B. R. Pitt, A. Lizonova, I. Kovesdi, and T. R. Billiar, "Adenoviral transfer of the inducible nitric oxide synthase gene blocks endothelial cell apoptosis," Journal of Surgery, vol. 122, no. 2, pp. 255-263, 1997.

[9] M. Kibbe, T. Billiar, and E. Tzeng, "Inducible nitric oxide synthase and vascular injury," Cardiovascular Research, vol. 43, no. 3, pp. 650-657, 1999.

[10] N. D. Tsihlis, C. S. Oustwani, A. K. Vavra et al., "Nitric oxide inhibits vascular smooth muscle cell proliferation and neointimal hyperplasia by increasing the ubiquitination and degradation of ubch10," Cell Biochemistry and Biophysics, vol. 60, no. 1-2, pp. 89-97, 2011.

[11] M. R. Kapadia, L. W. Chow, N. D. Tsihlis et al., "Nitric oxide and nanotechnology: a novel approach to inhibit neointimal hyperplasia," Journal of Vascular Surgery, vol. 47, no. 1, pp. 173-182, 2008.

[12] S. M. Yu, L. M. Hung, and C. C. Lin, "cGMP-elevating agents suppress proliferation of vascular smooth muscle cells by 
inhibiting the activation of epidermal growth factor signaling pathway," Circulation, vol. 95, no. 5, pp. 1269-1277, 1997.

[13] N. J. Boerth, N. B. Dey, T. L. Cornwell, and T. M. Lincoln, "Cyclic GMP-dependent protein kinase regulates vascular smooth muscle cell phenotype," Journal of Vascular Research, vol. 34, no. 4, pp. 245-259, 1997.

[14] T. L. Cornwell, E. Arnold, N. J. Boerth, and T. M. Lincoln, "Inhibition of smooth muscle cell growth by nitric oxide and activation of cAMP-dependent protein kinase by cGMP," American Journal of Physiology, vol. 267, no. 5, pp. C1405C1413, 1994.

[15] A. Ishida, T. Sasaguri, C. Kosaka, H. Nojima, and J. Ogata, "Induction of the cyclin-dependent kinase inhibitor p21(Sdi1/Cip1/Waf1) by nitric oxide-generating vasodilator in vascular smooth muscle cells," Journal of Biological Chemistry, vol. 272, no. 15, pp. 10050-10057, 1997.

[16] S. Y. Kang, V. B. Schini-Kerth, and N. D. Kim, "Ginsenosides of the protopanaxatriol group cause endothelium-dependent relaxation in the rat aorta," Life Sciences, vol. 56, no. 19, pp. 1577-1586, 1995.

[17] K. W. Leung, Y. K. Cheng, N. K. Mak, K. K. C. Chan, T. P. David Fan, and R. N. S. Wong, "Signaling pathway of ginsenoside-Rg1 leading to nitric oxide production in endothelial cells," FEBS Letters, vol. 580, no. 13, pp. 32113216, 2006.

[18] S. W. Han and H. Kim, "Ginsenosides stimulate endogenous production of nitric oxide in rat kidney," International Journal of Biochemistry and Cell Biology, vol. 28, no. 5, pp. 573-580, 1996.

[19] H. Chai, W. Zhou, P. Lin, A. Lumsden, Q. Yao, and C. Chen, "Ginsenosides block HIV protease inhibitor ritonavir-induced vascular dysfunction of porcine coronary arteries," American Journal of Physiology, vol. 288, no. 6, pp. H2965-H2971, 2005.

[20] X. Wang, S. Chu, T. Qian, J. Chen, and J. Zhang, "Ginsenoside Rg1 improves male copulatory behavior via nitric oxide/cyclic guanosine monophosphate pathway," The Journal of Sexual Medicine, vol. 7, no. 2, part 1, pp. 743-750, 2010.

[21] J. Deng, Y. W. Wang, W. M. Chen, Q. Wu, and X. N. Huang, "Role of nitric oxide in ginsenoside Rg1-induced protection against left ventricular hypertrophy produced by abdominal aorta coarctation in rats," Biological and Pharmaceutical Bulletin, vol. 33, no. 4, pp. 631-635, 2010.

[22] B. Li, Q. Wu, J. S. Shi et al., "Effects of protopine on intracellular calcium and the PKC activity of rat aorta smooth muscle," Acta Physiologica Sinica, vol. 57, no. 2, pp. 240-246, 2005.

[23] R. C. Braun-Dullaeus, M. J. Mann, and V. J. Dzau, "Cell cycle progression: new therapeutic target for vascular proliferative disease," Circulation, vol. 98, no. 1, pp. 82-89, 1998.

[24] V. Sriram and C. Patterson, "Cell cycle in vasculoproliferative diseases potential interventions and routes of delivery," Circulation, vol. 103, no. 19, pp. 2414-2419, 2001.

[25] G. A. Ferns, E. W. Raines, K. H. Sprugel, A. S. Motani, M. A. Reidy, and R. Ross, "Inhibition of neointimal smooth muscle accumulation after angioplasty by an antibody to PDGF," Science, vol. 253, no. 5024, pp. 1129-1132, 1991.

[26] R. Ross, "The pathogenesis of atherosclerosis: a perspective for the 1990s," Nature, vol. 362, no. 6423, pp. 801-809, 1993.

[27] R. Seger and E. G. Krebs, "The MAPK signaling cascade," FASEB Journal, vol. 9, no. 9, pp. 726-735, 1995.

[28] S. L. Pelech and J. S. Sanghera, "Mitogen-activated protein kinases: versatile transducers for cell signaling," Trends in Biochemical Sciences, vol. 17, no. 6, pp. 233-238, 1992.
[29] M. J. Pazin and L. T. Williams, "Triggering signaling cascades by receptor tyrosine kinases," Trends in Biochemical Sciences, vol. 17, no. 10, pp. 374-378, 1992.

[30] M. A. Moro, R. J. Russell, S. Cellek et al., "cGMP mediates the vascular and platelet actions of nitric oxide: confirmation using an inhibitor of the soluble guanylyl cyclase," Proceedings of the National Academy of Sciences of the United States of America, vol. 93, no. 4, pp. 1480-1485, 1996.

[31] L. Sandirasegarane and J. Diamond, "The nitric oxide donors, SNAP and DEA/NO, exert a negative inotropic effect in rat cardiomyocytes which is independent of cyclic GMP elevation," Journal of Molecular and Cellular Cardiology, vol. 31, no. 4, pp. 799-808, 1999.

[32] L. S. Chan, P. Y. Yue, N. K. Mak, and R. N. S. Wong, "Role of microRNA-214 in ginsenoside-Rg1-induced angiogenesis," European Journal of Pharmaceutical Sciences, vol. 38, no. 4, pp. 370-377, 2009.

[33] J. Y. Jeremy, D. Rowe, A. M. Emsley, and A. C. Newby, "Nitric oxide and the proliferation of vascular smooth muscle cells," Cardiovascular Research, vol. 43, no. 3, pp. 580-594, 1999.

[34] Y. F. Zhang, X. J. Fan, X. Li et al., "Ginsenoside Rg1 protects neurons from hypoxic-ischemic injury possibly by inhibiting $\mathrm{Ca}^{2+}$ influx through NMDA receptors and L-type voltagedependent $\mathrm{Ca}^{2+}$ channels," European Journal of Pharmacology, vol. 586, no. 1-3, pp. 90-99, 2008.

[35] N. Shukla, J. Y. Jeremy, P. Nicholl, B. Krijgsman, G. Stansby, and G. Hamilton, "Short-term exposure to low concentrations of thapsigargin inhibits replication of cultured human vascular smooth muscle cells," British Journal of Surgery, vol. 84, no. 3, pp. 325-330, 1997. 


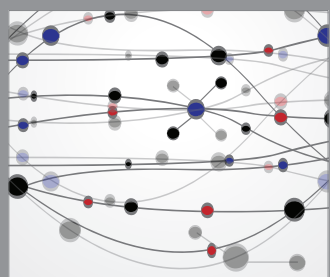

The Scientific World Journal
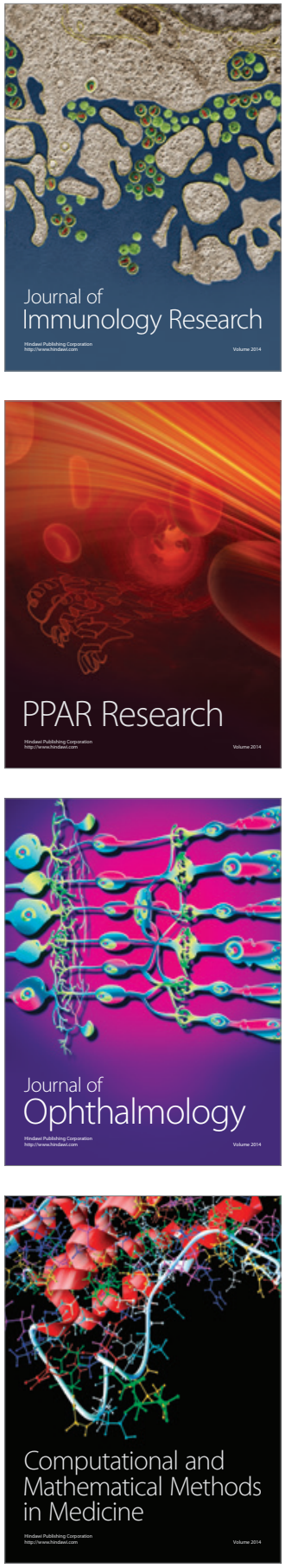

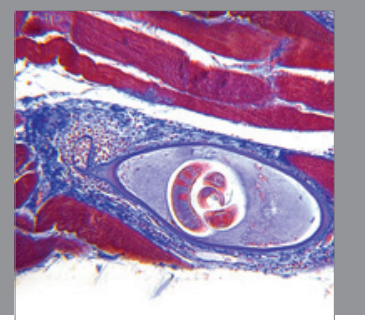

Gastroenterology

Research and Practice
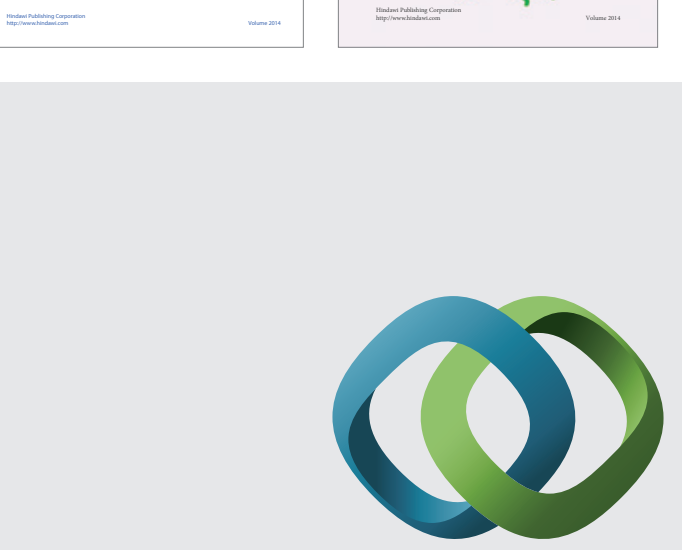

\section{Hindawi}

Submit your manuscripts at

http://www.hindawi.com
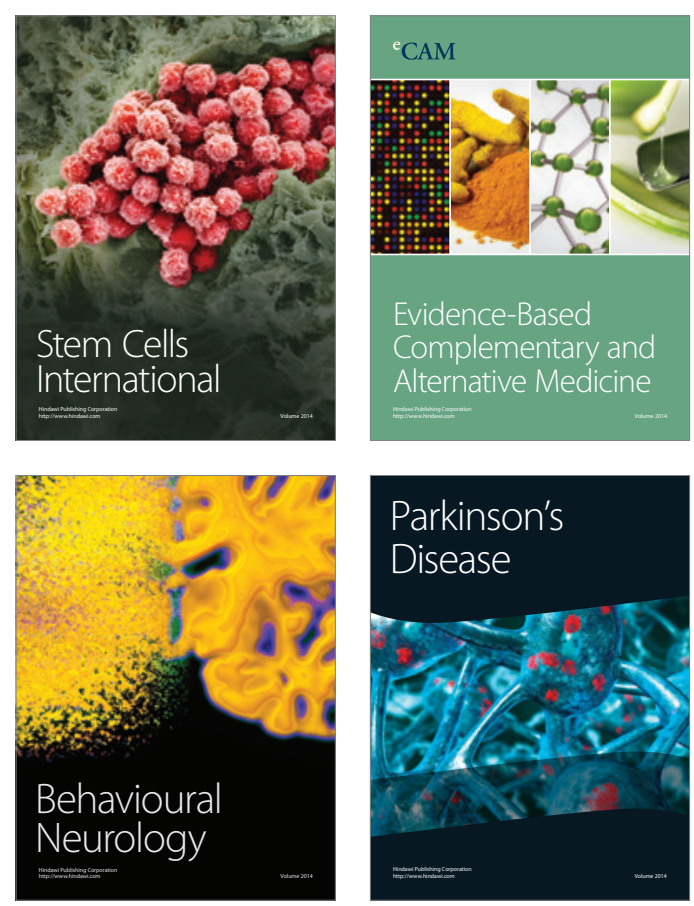

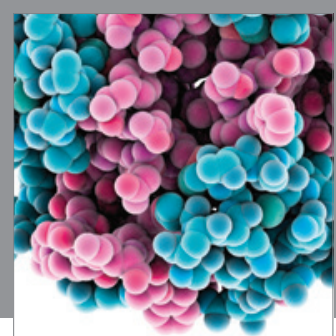

Journal of
Diabetes Research

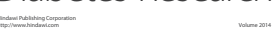

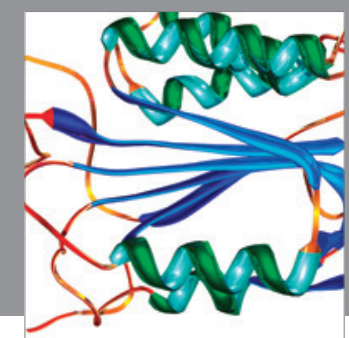

Disease Markers
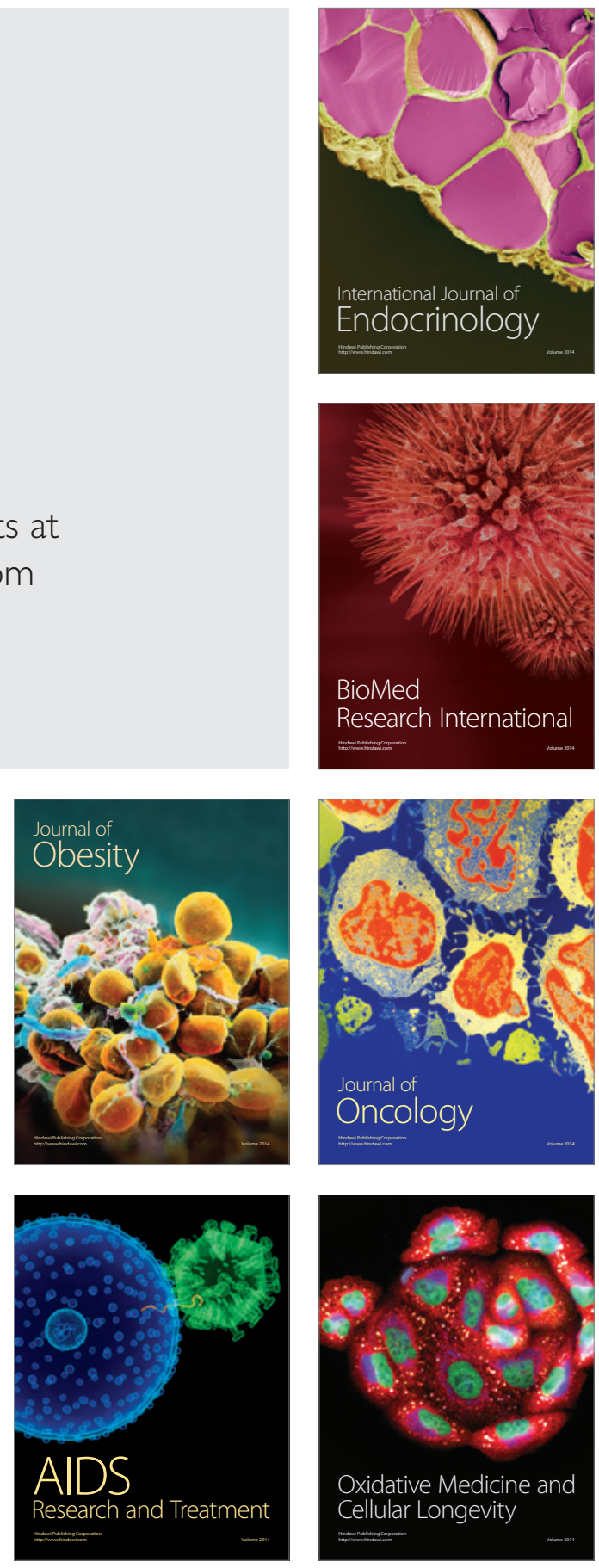